\title{
Purpura Fulminans in the Setting of Klebsiella Pneumoniae Bacteremia and Acetaminophen Overdose
}

\author{
Vincent Nguyen ${ }^{1}$, Janine A. Myint ${ }^{1}$, Marie Philipneri ${ }^{1}$ \\ 1. Department of Medicine, Division of Nephrology, Saint Louis University School of Medicine, Saint Louis, USA
}

Corresponding author: Marie Philipneri, marie.philipneri@health.slu.edu

\begin{abstract}
Purpura fulminans (PF) is a rare, life-threatening disorder characterized by disseminated intravascular coagulation (DIC), circulatory collapse, and hemorrhagic cutaneous purpura. It typically occurs secondary to acute infections, usually meningococcal septicemia, although there are also congenital and acquired causes. We report a case of a 56-year old female who presented to our institution with clinical signs of PF in the setting of acetaminophen overdose and Klebsiella pneumoniae sepsis. Given the rarity of the disease, we also review cases of PF in similar clinical scenarios that have been described in the literature.
\end{abstract}

Categories: Dermatology, Internal Medicine, Hematology

Keywords: purpura fulminans, acute infectious purpura fulminans, disseminated intravascular coagulation, klebsiella pneumoniae, acetaminophen toxicity

\section{Introduction}

Purpura fulminans (PF) is a rare, life-threatening disorder with a mortality rate of up to $60 \%[1,2]$. It is characterized by disseminated intravascular coagulation (DIC), circulatory collapse, and dermal vascular thrombosis that results in hemorrhagic cutaneous purpura in the trunk and limbs [1, 3-6]. PF is typically seen in three clinical settings; inherited or acquired coagulation disorder, acute infection, or idiopathic [3, 7]. Most commonly, it is seen in children and is due to endotoxin-production from meningococcal disease [1, 3].

Cutaneous manifestations of PF include widespread ecchymoses, hemorrhagic bullae, and epidermal necrosis [6]. Patients initially present with erythema and petechiae that evolve into ecchymoses and purpuric plaques. With time, there is symmetric gangrene of distal extremities that extend proximally [4, 8]. Histopathology reveals dermal vascular thrombosis with the presence of microthrombi in the dermal blood vessels $[1,4,8]$.

Review began 10/15/2020 Review ended 11/06/2020 Published 11/22/2020

\section{() Copyright 2020}

Nguyen et al. This is an open access article distributed under the terms of the Creative Commons Attribution License CC-BY 4.0., which permits unrestricted use, distribution, and reproduction in any medium, provided the original author and source are credited.
Because of the high mortality rate, it is imperative that timely diagnosis and treatment of PF are undertaken. It is also important to point out atypical presentations, such as PF in adults, and potential causes other than meningococcal disease or coagulation disorder.

In our case report, we present a case of PF in the setting of Klebsiella pneumoniae and acetaminophen toxicity.

\section{Case Presentation}

A 56-year-old female with a past medical history significant for depression, gastric cancer status post partial gastrectomy, and nonalcoholic steatohepatitis (NASH) presented as a transfer from an outside hospital for acute liver failure, concerning for acetaminophen overdose. She was noted to have altered mental status with laboratory studies revealing transaminitis and elevated acetaminophen level indicating "possible hepatic toxicity" per the Rumack-Matthew nomogram. She was admitted to the intensive care unit (ICU) with shock and multi-organ failure requiring vasopressors and mechanical ventilation. $\mathrm{N}$-acetylcysteine (NAC) was administered for possible acetaminophen overdose, followed by Continuous Renal Replacement Therapy (CRRT) for worsening metabolic panel due to acute kidney injury. Physical examination was significant for cold bilateral distal extremities and skin mottling in the upper and lower extremities which progressed to involve the majority of the body over the course of several hours. Computerized tomography (CT) scans of chest, abdomen, and pelvis were notable for bilateral lower lobe lung consolidations with scattered ground-glass opacities, hepatomegaly, bowel wall thickening, and cortical necrosis in both kidneys. Blood cultures were positive for Klebsiella pneumoniae and she was started on meropenem and vancomycin. Laboratory tests revealed anemia, thrombocytopenia, elevated PT/PTT, elevated d-dimer, and low fibrinogen concerning for DIC. Skin mottling continued to worsen, later developing bullae over the bilateral anterior thighs. Dermatology was consulted and noted retiform purpura involving bilateral thighs, legs, feet, arms, hands, the tip of the nose, upper ear, and lower abdomen (Figure 1). Gangrenous changes were observed over the fingers and nails on both hands. Left upper arm biopsy demonstrated epidermal 


\section{Cureus}

necrosis with extravasated red blood cells and scattered microthrombi in the papillary dermis. She was started on therapeutic heparin at this time although this was later discontinued. Plastic Surgery and Interventional Radiology were later consulted for management of gangrenous hands, but the decision was made to allow the necrotic areas to declare with no acute intervention (Figure 2). Thrombophilia and autoimmune evaluation were remarkable for positive lupus anticoagulant and decreased protein C and S activity, albeit she was receiving therapeutic heparin at this time. After initiation of antibiotics, she continued to improve and was stepped down from ICU to floor with wound care. Some return of blood flow to the proximal part of her hands was noted and she was discharged to a Long-term Acute Care (LTAC) facility. She was readmitted to the hospital less than a month later for right elbow disarticulation and lefthand amputation for progression of dry gangrene to wet gangrene.

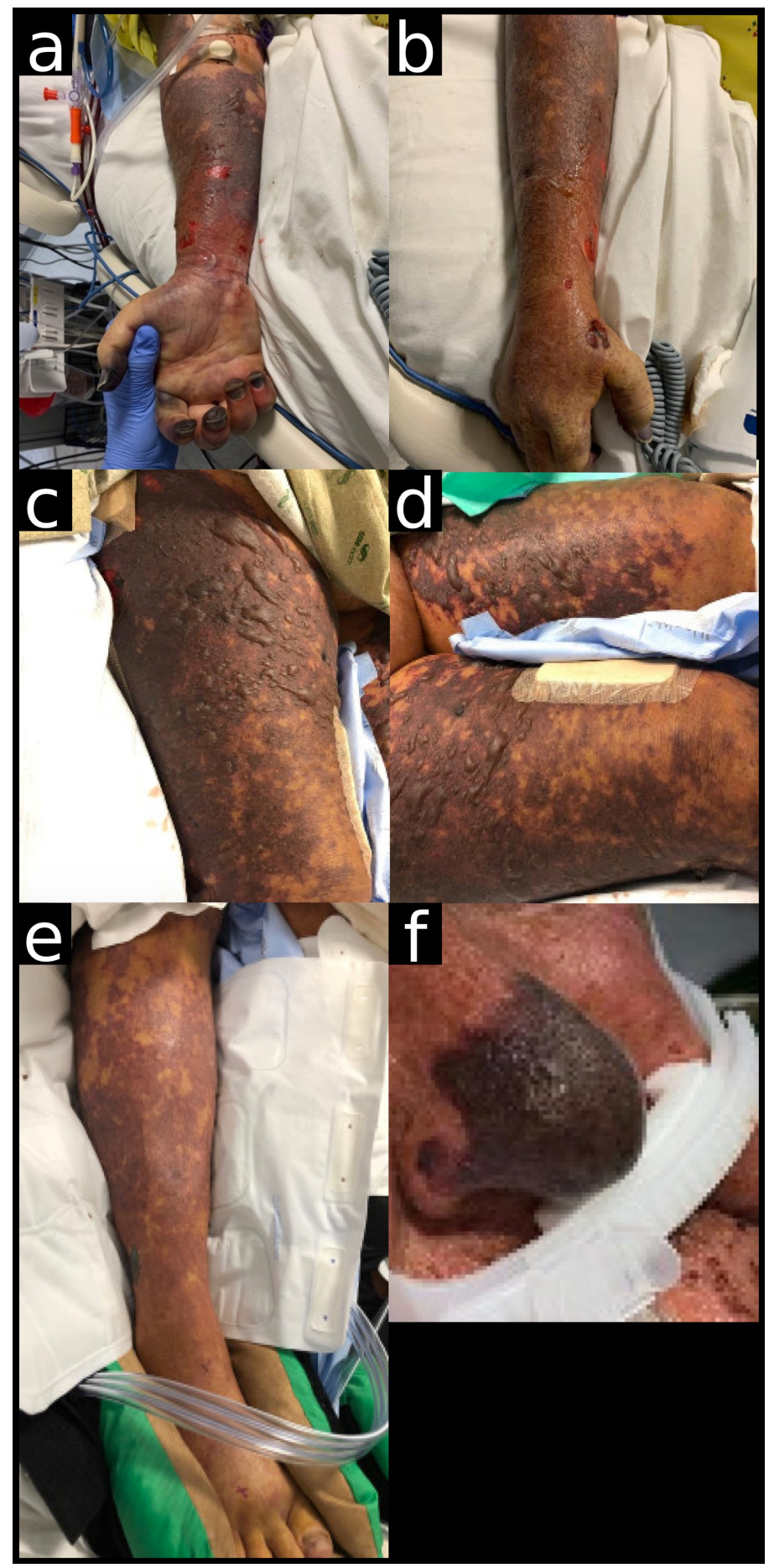

FIGURE 1: Early presentation of cutaneous findings. a,b. Retiform purpura on right arm with gangrenous changes in nails. c,d,e. Bullae on bilateral thighs and purpura extending down to toes. f. Purpura on the tip of the nose. 


\section{Cureus}

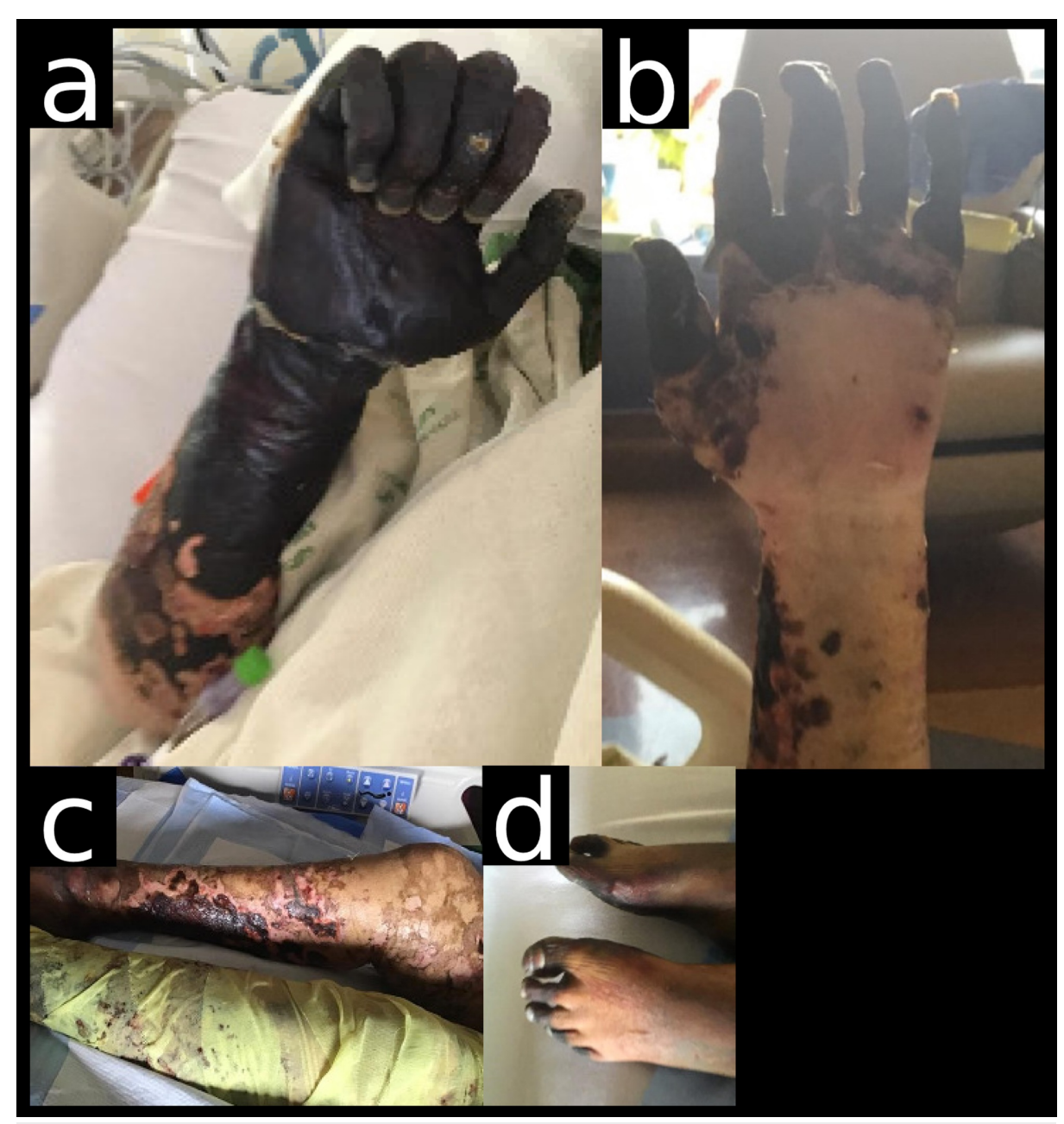

FIGURE 2: Late presentation of cutaneous findings. a. Dry gangrene of the right forearm/hand. b. Dry gangrene of the left hand. c. Gangrenous changes to the legs and distal toes bilaterally.

\section{Discussion}

We describe a case of rapidly progressive retiform purpura in a patient who was found to have Klebsiella pneumoniae bacteremia. Two additional differential diagnoses were considered at the time of presentation; vasopressor-induced necrosis and vasculitis. Vasopressor-induced necrosis was a consideration given her gangrenous hands, although unlikely because of the hemorrhagic bullae formation in early presentation, rapid spread to her proximal extremities, and laboratory findings suggestive of DIC. Vasculitis was also considered but less likely given the unremarkable autoimmune workup. She did have a positive lupus anticoagulant, but according to Colling and Bendapudi, lupus anticoagulant can be positive at the time of presentation in patients with $\mathrm{PF}[1]$.

Several studies have noted that laboratory findings associated with PF include prolonged coagulation times, decreased fibrinogen, elevated d-dimer, abnormalities in protein C function, and thrombocytopenia [1, 5]. As for skin biopsy, the presence of microthrombi in dermal blood vessels is typical $[1,4,5]$. In our patient, DIC, decreased protein C and S activity, skin biopsy findings, and clinical improvement after antibiotic initiation made PF secondary to Klebsiella pneumoniae sepsis the most likely diagnosis. There have been a few case reports of PF in the setting of Klebsiella species infection (Table 1). In one case report of PF caused by Klebsiella pneumoniae, there was also involvement of the nose as seen in our patient, which was deemed an unusual location of PF manifestation. 


\section{Cureus}

\begin{tabular}{|c|c|c|c|c|}
\hline Author & $\begin{array}{l}\text { Age at } \\
\text { diagnosis }\end{array}$ & Likely Cause(s) & Management & $\begin{array}{l}\text { Outcomes (including } \\
\text { complications) }\end{array}$ \\
\hline $\begin{array}{l}\text { Tsubouchi et } \\
\text { al. (2019) [9] }\end{array}$ & $\begin{array}{l}75-\text { year } \\
\text { old } \\
\text { woman }\end{array}$ & Klebsiella Oxytoca & Intensive care & Death \\
\hline $\begin{array}{l}\text { Disse et al. } \\
\text { (2018) [2] }\end{array}$ & $\begin{array}{l}\text { 17-day } \\
\text { old } \\
\text { neonate }\end{array}$ & $\begin{array}{l}\text { Klebsiella Oxytoca sepsis } \\
\text { from central venous catheter }\end{array}$ & $\begin{array}{l}\text { Broad-spectrum antibiotics, ventilation, } \\
\text { diuretics, protein } C \text { substitution, burn protocol }\end{array}$ & $\begin{array}{l}\text { Limbs successfully } \\
\text { preserved with } \\
\text { scarring }\end{array}$ \\
\hline $\begin{array}{l}\text { Singh and } \\
\text { Kampani } \\
\text { (2018) [7] }\end{array}$ & $\begin{array}{l}\text { 19-year } \\
\text { old } \\
\text { female }\end{array}$ & Klebsiella Pneumoniae & IV fluids, broad-spectrum antibiotics, platelets & Unknown \\
\hline $\begin{array}{l}\text { Umar (2018) } \\
\text { [10] }\end{array}$ & $\begin{array}{l}\text { 2-month } \\
\text { old boy }\end{array}$ & Klebsiella Pneumoniae & $\begin{array}{l}\text { Ceftriaxone, blood transfusions, FFP } \\
\text { considered }\end{array}$ & $\begin{array}{l}\text { Parents left against } \\
\text { medical advice (AMA) }\end{array}$ \\
\hline $\begin{array}{l}\text { Guccione et al. } \\
\text { (1993) [8] }\end{array}$ & $\begin{array}{l}\text { 32-year } \\
\text { old } \\
\text { woman }\end{array}$ & $\begin{array}{l}\text { Acetaminophen and Alcohol } \\
\text { toxicity }\end{array}$ & Heparin, Vitamin K, Cefuroxime & $\begin{array}{l}\text { Resolution of Purpuric } \\
\text { Lesions }\end{array}$ \\
\hline
\end{tabular}

\section{TABLE 1: Literature review of cases of PF from Klebsiella or Acetaminophen}

This presentation is most consistent with acute infectious PF. Several researchers have noted that during infection, bacterial endotoxins induce coagulation secondary to consumption of protein C and S [5]. This results in an acquired hypercoagulable state that leads to thromboses in dermal vessels, DIC, and hemorrhagic skin necrosis.

Our patient also had signs of concomitant acetaminophen toxicity that may have contributed to the development of PF. Although her transaminitis was not very high to suggest acute liver failure, the acetaminophen-induced liver injury may have led to further decline in protein $\mathrm{C}$ and $\mathrm{S}$ function. Guccione et al. published a report of PF with acquired protein $\mathrm{C}$ and $\mathrm{S}$ deficiency induced by alcohol and acetaminophen [8]. They speculated that the reduction in hepatic glutathione caused by acetaminophen toxicity led to the impairment of anticoagulation proteins synthesis, resulting in the activation of the DIC cascade and Purpura Fulminans [8].

In acute infectious PF, the treatment is to address the underlying cause with antibiotic therapy in addition to supportive care. Currently, there is no consensus on the treatment of PF. A few treatments that have been utilized include broad-spectrum antibiotics, anticoagulation, protein C, platelets, and FFP [1, 2, 5-8]. There may be a role for protein $\mathrm{C}$ replacement as seen in a small study where all patients survived despite high predicted mortality [11]. The RESOLVE study found that the use of protein C in the treatment of severe sepsis in children resulted in no significant improvement in organ failure or 28-day mortality but increased intracranial hemorrhage. Although this study did not analyze the use of protein C in PF specifically, there is enough overlap to suggest that protein C should be used with caution [5].

\section{Conclusions}

Purpura fulminans is a rare, yet life-threatening condition that can result in DIC, hemodynamic collapse, and hemorrhagic cutaneous necrosis. PF is mostly seen in children in the setting of meningococcus bacteremia. Diagnostic delay can lead to major adverse clinical consequences to the patient, such as amputation of limbs and death. Our case presents a unique example of an adult with signs and symptoms of Purpura Fulminans in the setting of Klebsiella pneumoniae bacteremia and Acetaminophen toxicity. This case emphasizes the importance of considering Purpura fulminans in adults with acquired protein $\mathrm{C}$ and $\mathrm{S}$ deficiency states, including certain bacterial infections and compromised liver function.

\section{Additional Information \\ Disclosures}

Human subjects: Consent was obtained by all participants in this study. Conflicts of interest: In compliance with the ICMJE uniform disclosure form, all authors declare the following: Payment/services info: All authors have declared that no financial support was received from any organization for the submitted work. Financial relationships: All authors have declared that they have no financial 
relationships at present or within the previous three years with any organizations that might have an interest in the submitted work. Other relationships: All authors have declared that there are no other relationships or activities that could appear to have influenced the submitted work.

\section{References}

1. Colling ME, Bendapudi PK: Purpura fulminans: mechanism and management of dysregulated hemostasis . Transfus Med Rev. 2018, 32:69-76. 10.1016/j.tmrv.2017.10.001

2. Disse SC, Meyer S, Baghai-Arassi A: Sepsis-associated purpura fulminans due to klebsiella oxytoca. Dtsch Arztebl Int. 2018, 115:784. 10.3238/arztebl.2018.0784a

3. Alsharif SH, Al-Omair A, Andijani F: Uncommon location of purpura fulminans: case report and literature review. Case Rep Dermatol. 2020, 12:5-11. 10.1159/000505476

4. Brozyna JR, Sardiña LA, Sharma A, Theil K, Bergfeld W: Acute purpura fulminans - a rare cause of skin necrosis: a single institution clinicopathological experience. J Cutan Pathol. 2020, 10.1111/cup.13732

5. Chalmers E, Cooper P, Forman K, et al.: Purpura fulminans: recognition, diagnosis and management . Arch Dis Child. 2011, 96:1066-71. 10.1136/adc.2010.199919

6. Kosaraju N, Korrapati V, Thomas A, et al.: Adult purpura fulminans associated with non-steroidal antiinflammatory drug use. J Postgrad Med. 2011, 57:145-6. 10.4103/0022-3859.81876

7. Singh P, Kampani G: Acute infectious purpura fulminans due to klebsiella pneumoniae . Journal of Medical Science And Clinical Research. 2018, 6:10.18535/jmscr/v6i1.156

8. Guccione JL, Zemtsov A, Cobos E, et al.: Acquired purpura fulminans induced by alcohol and acetaminophen. Successful treatment with heparin and vitamin K. Arch Dermatol. 1993, 129:1267-9. 10.1001/archderm.1993.01680310037005

9. Tsubouchi N, Tsurukiri J, Numata J, Sano H: Acute infectious purpura fulminans caused by klebsiella oxytoca. Intern Med. 2019, 58:1801-1802. 10.2169/internalmedicine.2350-18

10. Umar LW, Ya'uba MS, Olorukooba AA, Abubakar Y, Mohammed AJ, Chom ND: Purpura fulminans with disseminated intravascular coagulopathy and symmetric peripheral gangrene complicating sepsis in an infant: a case report. Ann Med Health Sci Res. 2017, 7:69-72.

11. Smith OP, White B, Vaughan D, Rafferty M, Claffey L, Lyons B, Casey W: Use of protein-C concentrate, heparin, and haemodiafiltration in meningococcus-induced purpura fulminans. Lancet. 1997, 350:1590-3. 10.1016/s0140-6736(97)06356-3 